\title{
Numerical simulation of baseflow modification due to effects of sediment yield
}

\author{
BML Mwaka \\ DWAF, Water Utilisation, Private Bag X313, Pretoria 0001, South Africa
}

\begin{abstract}
Alluvial rivers re-shape their own geometry by depositing sediments or eroding the channel when their dynamic equilibrium is disturbed. Such adjustments may induce river-bed and water-level profiles that have significant effects on the interaction of streams and aquifers that are connected hydraulically. Physically-based mathematical modelling affords the opportunity to look at this kind of interaction, which should be simulated by deterministic responses of both water and fluvial processes. In addition to simulating the streamflow and groundwater dynamics, the model should also be capable of tracking down the level of the coupling interface boundary.

A procedure for modelling alluvial stream-aquifer interaction - MASAI - has been developed to enable the coupling of unstable alluvial stream-aquifer interacting systems. Application of MASAI to hypothetical alluvial stream-aquifer systems reveals the complex relationships between individual elements of the systems, and highlights the influence of sediment yield on baseflow.
\end{abstract}

\section{Introduction}

Most alluvial rivers only partially penetrate their underlying aquifers, but the exchange of water between them can have significant effects on streamflow as shown, for example, by Hughes and Sami (1992). Furthermore, alluvial rivers normally involve transportation of sediment materials, and if the dynamic equilibrium of such rivers is disturbed, the rivers tend to adjust to new pseudo-equilibrium conditions by depositing the sediments or scouring the bed. Either of these sedimentary processes can have additional effects on the interaction between the rivers and aquifers that are connected hydraulically. Many case histories of channel adjustments because of disturbances in the rivers are well-documented (e.g. Chang, 1988; Petts and Foster, 1992).

The exchange of water between streamflow and groundwater is generally a function of the difference between the water levels in the aquifer and the river. The actual magnitude of flow depends on the local geology, particularly the hydraulic conductivity of the interface boundary layer at the bottom of the river. The process of interaction over spatially varied channel boundaries is difficult to examine, and further difficulties arise in the case of alluvial channels whose hydraulic and fluvial conditions are not in equilibrium.

Physically-based mathematical modelling affords an opportunity to explore the fundamental relationships between various elements of stream-aquifer systems. It also offers ways of studying short- and long-term hydrological responses due to changes in the hydrological systems. However, stream-aquifer interaction and sediment routing models have traditionally been developed separately, with their interdependence either not considered at all, or accounted for only by simple assumptions. To examine the dynamics of water between alluvial rivers and riparian aquifers, it is necessary to develop a mathematical model that simulates the variation of both streamflow and groundwater levels, and also the transient adjustments of the river bed arising from sedimentation.

(012) 336- 8188; fax (012) 323- 5041; e-mail: qhd@ dwaf.pwv.gov.za Received 19 November 1999, accepted in revised form 25 January 2001.
This concept is an enhancement of existing mathematical modelling of stream-aquifer interaction, which has previously been confined to regime river problems that performed the simulations, assuming pre-defined rigid river-bed elevation profiles (e.g. Swain and Wexler, 1996). Likewise, water and sediment routing simulations in alluvial channels have previously been performed assuming groundwater contribution as a pre-defined lateral flow obtained as a constant calibration parameter (e.g. Chang, 1982). When streamflow and sediment routing is performed for rocky basins with river beds that have very low permeability, or when stream-aquifer interaction is simulated for stable channels with negligible sediment yield, then errors introduced by adopting the standard assumptions will not be significant. When, however, a modelling exercise concerns conjunctive water use in alluvial stream-aquifer systems with notable sediment yield, the errors may be sufficiently large as to invalidate the exercise. Younger et. al. (1993) and Crerar et al. (1988), for example, have previously shown that the sedimentation on river beds can have significant effects on stream-aquifer interactions.

\section{Justification}

MASAI is suited to the evaluation of soil and water conservation practices in riparian plains, inasmuch as changes in land use and river engineering affect streamflow and sediment yield. In fact streamflow and sediment yield, in their various aspects, are recognised diagnostic criteria for the assessment of watershed conditions, and for the effectiveness of catchment and river management strategies. Total yearly amounts of both water and sediment yields, seasonal regularity, frequencies and extremes of high and low discharges provide useful indications of the net result of management practices.

Analysis of baseflow and sediment discharges can provide a basis for predicting the hydrological and fluvial impacts of management practices on stream-aquifer systems. Variation of either water flow or sediment yield in turn affects sediment transport through downstream reaches. Whenever the sediments transported into a given reach amount to less than the transport capacity of the channel, scour occurs, whereas when the incoming sediment load 
is greater than the transport capacity, the sediments are deposited.

Simulation by MASAI is capable of tracking deposition or scour in channel beds, along with their influence on stream-aquifer interaction or baseflow. In this modelling, however, only changes in the elevation profiles of the river bed are tracked during simulations. The other boundary parameters, like the hydraulic conductivity and Manning's roughness, which have also been identified as having significant influence on stream-aquifer interaction (Cunningham and Sinclair, 1979), cannot be tracked in the simulations explicitly. It is nevertheless possible to correlate them as functions of the depth of the alluvial riverbed accumulations (Sharp, 1977).

A baseflow recession curve shows the transient variation of groundwater contribution into a river. In essence it is a measure of the rate of drainage of groundwater from adjoining aquifers. Previous analyses of streamflow hydrographs have produced idealised recession curves according to the decay relationship of Eq. (1) (Chow et al., 1988):

$$
Q_{b}=Q_{0} \cdot e^{-\alpha t}
$$

where:

$\mathrm{Q}_{\mathrm{b}}=$ baseflow after a time period $\mathrm{t}$,

$\mathrm{Q}_{\mathrm{o}}=$ baseflow at the start of the time period,

$\mathrm{a}=$ recession constant representative of the system and

$e=$ natural logarithm.

However, any phenomenon that changes the pressure gradient between streamflow and groundwater will also cause the baseflow to vary. Flood events through rivers and diffuse recharges into riparian aquifers are among the major causes of baseflow variation. Todd (1955) and Singh (1968), for example, have previously investigated and shown how both factors affect baseflow recession. Likewise, any kind of sedimentary accumulation between the river and the aquifer media will cause the pressure gradient to change and thus affect seepage rates across their boundaries. Sedimentation, therefore, has the potential to cause not only evolution/scour of river-bed elevation, but also waxing and waning of groundwater recharge capacity in riparian alluvial aquifers. Simulation by MASAI is capable of tracing these processes.

Its application, however, has more meaning in river systems that are likely to have upstream land-use changes. The problem of exactly how streamflow and/or sediment yields are affected by land-use is very complex and has not been attempted. Nonetheless, a qualitative picture of how sediment yields affect streamflow, and their various ramifications have been disclosed to give a rational basis for interpreting the relevant data and plans for developments on such river systems.

\section{Modelling procedure}

The mathematical model is accomplished by solving simultaneously the numerical translations of the Saint Venant equations and the sediment continuity equation which govern the 1-D spatially variant transient flows in open channels, and the linearised Boussinesq equation describing the 2-D transient groundwater flow. The numerical solutions of streamflow and groundwater are then linked through a time-dependent interface boundary layer in order to constitute a mathematical procedure for MASAI.

Mathematical models for water and sediment routing on the one hand, and stream-aquifer interaction on the other, are welldeveloped and documented (e.g. Chang, 1982; Swain and Wexler, 1996). This paper focuses on the coupling of streamflow and groundwater through loose boundaries of alluvial rivers that are subject to variable sediment-laden discharges. Detailed modelling of sediment routing or stream-aquifer interaction, therefore, will not be reproduced. A brief outline of the models is presented, followed by a full formulation for coupling unstable alluvial stream-aquifer interacting systems.

\section{Water routing}

Water routing describes the temporal and spatial variation of stage, discharge, energy gradient, and other hydraulic variables in a channel. The differential equations describing streamflow routing are based on the Saint Venant's equations of continuity and momentum of water, Eqs. (2) and (3), respectively (Strelkoff, 1969):

$$
\begin{aligned}
& \frac{\partial Q}{\partial x}+\frac{\partial A}{\partial t}-q=0 \\
& \frac{\partial Q}{\partial t}+\frac{\partial}{\partial x}\left(\frac{Q^{2}}{A}\right)+g A \frac{\partial H}{\partial x}-g A S_{0}+g A S_{f}-q u_{1}=0 \\
& \mathrm{Q}=\text { discharge } \\
& \mathrm{A}=\text { cross-sectional area of flow } \\
& \mathrm{t}=\text { time } \\
& \mathrm{x}=\text { distance along the discharge center-line } \\
& \mathrm{H}=\text { depth of flow } \\
& \mathrm{q}=\text { lateral discharge per unit length (which in this case is } \\
& \mathrm{u}_{1}=\text { velocity component of lateral inflow in the x-axis } \\
& \mathrm{g}=\text { direction } \\
& \mathrm{S}_{\mathrm{f}}=\text { eneleration due to gravity } \\
& \mathrm{S}_{\mathrm{o}}=\text { bed slope. }
\end{aligned}
$$$$
\text { where: }
$$

Solutions to these equations are normally achieved through numerical techniques. Details of the conversion of the differential into numerical equations, and the implicit four-point finite difference technique used to solve the numerical equations are available, e.g. Amein and Fang (1970) and Mwaka (1995).

\section{Sediment routing}

Sediment routing accounts for changes in sediment transport, bed elevation and slope along the channel at required time intervals. The differential equation describing the sedimentation is based on the sediment continuity equation, Eq. (4):

$$
\frac{\partial Q_{s}}{\partial x}+(1-\lambda) \frac{\partial A_{b}}{\partial t}-q_{s}=0
$$

where:

$\mathrm{Q}_{\mathrm{s}}=$ sediment discharge load

$1=$ is the porosity of bed material

$\mathrm{q}_{\mathrm{s}}=$ lateral inflow rate of the sediments per unit length

$\mathrm{A}_{\mathrm{b}}=$ cross-sectional area of the channel, which results from accumulated erosion or deposition.

The sediment load $\mathrm{Q}_{\mathrm{s}}$ can be estimated by any appropriate sediment transport function. Derivation and numerical solution of the sediment routing equation, and the sediment transport function used in this study can be found in Chang (1982) and Ackers -White (1973), respectively. 


\section{Groundwater flow}

Groundwater involves the flow and storage of water in saturated porous soil formations. Its flow is dependent on the hydraulic gradients in the aquifer. The potential head and flow of groundwater on flood plains are estimated by Boussinesq's equation for groundwater, Eq. (5)

$$
T\left(\frac{\partial^{2} \psi}{\partial x^{2}}+\frac{\partial^{2} \psi}{\partial y^{2}}\right)=S_{y} \frac{\partial \psi}{\partial t}+I(x, y, t)
$$

And for the part of the aquifer confined beneath the river, Eq. (5) is modified to:

$$
T\left(\frac{\partial^{2} \psi}{\partial x^{2}}+\frac{\partial^{2} \psi}{\partial y^{2}}\right)=S_{c} \frac{\partial \psi}{\partial t}+q\left(x, t, K_{1}, \Delta H, \Delta Z_{1}\right)
$$

where:

$$
\begin{aligned}
& \mathrm{Y}=\text { groundwater potential head } \\
& \mathrm{T}=\mathrm{K}_{2} m=\text { aquifer transmissivity } \\
& \mathrm{K}_{2} \text { and } m=\text { aquifer hydraulic conductivity and the } \\
& \mathrm{S}=\text { storativity of the confined aquifer } \\
& \mathrm{S}_{\mathrm{y}} \quad=\text { specific yield of the unconfined aquifer } \\
& \mathrm{q}=\text { seepage from the river } \\
& \mathrm{Z}_{1}=\text { thickness of the riverbed sediment layer } \\
& \mathrm{K}_{1}=\text { hydraulic conductivity of the riverbed sediment } \\
& \text { layer } \\
& \text { I }=\text { vertical infiltration into the unconfined aquifer }
\end{aligned}
$$

Detailed derivation of the equations can be found, for example, in Bear (1972). The numerical solution of the iterative successive over-relaxation method applied to solve them is presented in Wang and Anderson (1982).

\section{Coupling alluvial stream-aquifer interacting systems}

The formulation developed here builds logically upon earlier internal coupling techniques, first introduced by Pinder and Sauer (1971), by including an innovative representation for an unsteady streambed conductance. By assuming that the riverbed is lined with a thin layer of sediments of thickness $Z_{1}$ and hydraulic conductivity $\mathrm{K}_{1}$, they obtained a coupling formula by applying Darcy's law, given as:

$$
q=\frac{K_{1}}{Z_{1}}(\Delta H)
$$

where:

$\mathrm{q}$ is seepage flow per unit area of the sediment layer

$\mathrm{DH}$ is the hydraulic head across the layer.

The same equation can be extended to relate the total hydraulic head causing a seepage flow $\mathrm{q}$ through $\mathrm{n}$ layers of porous media, as:

$$
\sum_{i=1}^{n}(\Delta H)_{i}=q \sum_{i=1}^{n} \frac{Z_{i}}{K_{i}}
$$

where:

$$
\begin{array}{ll}
\mathrm{K}_{\mathrm{i}} & =\text { hydraulic conductivity of individual medium } \\
\mathrm{Z}_{\mathrm{i}} & =\text { thickness of individual medium } \\
(\mathrm{DH})_{\mathrm{i}} & =\text { head difference across each medium } \\
\mathrm{n} & =\text { total number of the porous media. }
\end{array}
$$

Considering a recharging stream, and assuming that seepage from the river is predominantly vertical through the channel bed (Fig. 1a), the recharge flow can be expressed as:

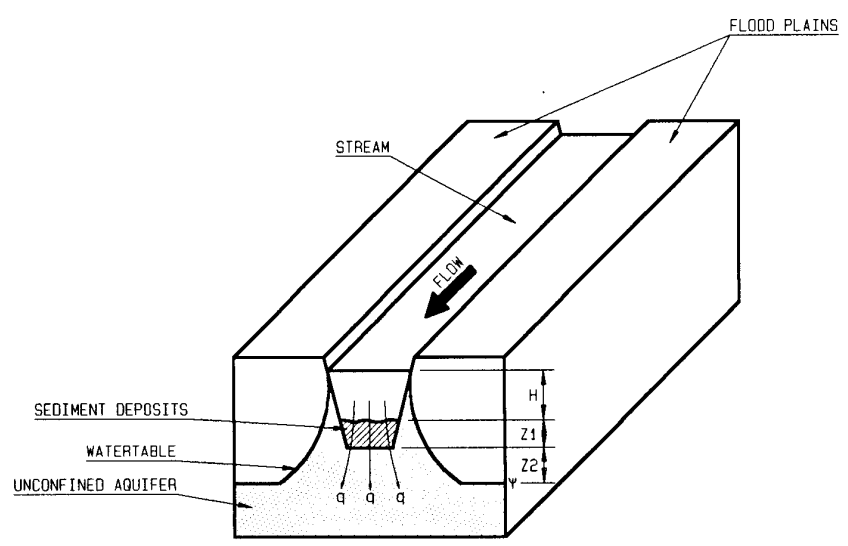

H = DEPTH OF STREAMFLOW

$21=$ THICKNESS OF SEDIMENT LAYER

$Z 2=$ DEPTH OF AQUIFER TO GROUNDWATER AT Y

$\psi$ = LEVEL OF GROUNDWATER POTENTIAL HEAD

$a=$ GROUNDWATER RECHARGE. FLOWS

\section{Figure 1a}

A schematic sketch of an influent river with sediment deposits on the river bed

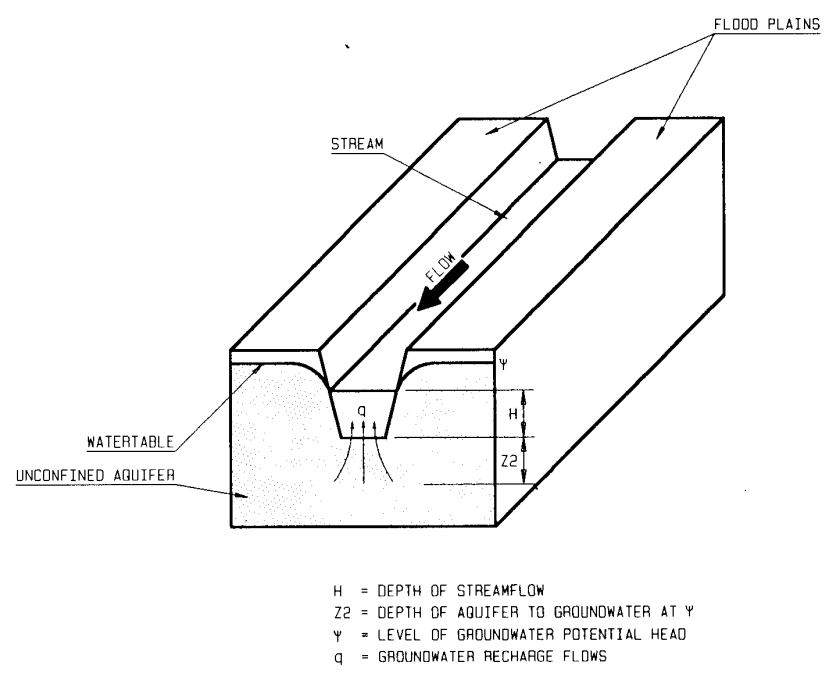

Figure 1b

A schematic sketch of an effluent river without deposits on the river bed

$$
q=\frac{\sum_{i=1}^{n}(\Delta H)_{i}}{\sum_{i=1}^{n} \frac{Z_{i}}{K_{i}}}
$$

The assumption of predominantly vertical flow is reasonable because, relative to river banks, riverbeds have a greater surface area, are closer to the zone of higher hydraulic conductivity and maximum pressure head acts on the bed. In MASAI, two porous media comprising a river-bed sediment layer and an alluvial aquifer medium are assumed (Fig. 1a). Then:

$$
q=\frac{\sum_{i=1}^{2}(\Delta H)_{i}}{\frac{1}{k_{1}}+\frac{1}{k_{2}}}
$$


or:

$$
q=\frac{k_{1} k_{2}}{k_{1}+k_{2}} \sum_{i=1}^{2}(\Delta H)_{i}
$$

where:

$\mathrm{k}_{1}$ and $\mathrm{k}_{2}$ are coefficients given as:

$$
\begin{aligned}
& \mathrm{k}_{1}=\mathrm{K}_{1} / \mathrm{Z}_{1} \\
& \mathrm{k}_{2}=\mathrm{K}_{2} / \mathrm{Z}_{2} .
\end{aligned}
$$

If a specific sediment seepage resistance is defined as $z=1 / K_{1}$ so that $\mathrm{k}_{1}=1 /\left(\mathrm{z} \cdot \mathrm{Z}_{1}\right)$, and assuming that the pressure head in the aquifer at the reference level is $\mathrm{y}_{\mathrm{a}}$, so that $\mathrm{S}(\mathrm{DH})_{\mathrm{i}}=\left(\mathrm{H}+\mathrm{Z}_{1}+\mathrm{Z}_{2}-\mathrm{y}_{\mathrm{a}}\right)$, then:

$$
q=\frac{k_{2}}{1+\zeta Z_{1} k_{2}}\left(H+Z_{1}+Z_{2}-\psi_{a}\right)
$$

or

$$
q=\frac{k_{2}}{Z_{2}}(\Delta h)
$$

which is similar to Eq. (7), with $\mathrm{k}_{2}=\mathrm{K}_{2} / \mathrm{Z}_{2}, \mathrm{z}_{2}=\left(1+\mathrm{zZ}_{1} \mathrm{k}_{2}\right)$ and (Dh) $=\left(\mathrm{H}+\mathrm{Z}_{1}+\mathrm{Z}_{2}-\mathrm{y}_{\mathrm{a}}\right)$.

Here, the relationship is described by contemporary conditions of the streambed, besides those of the streamflow and groundwater conditions. The formula is in an appropriate form that can be applied to account for transient seepage flows and link alluvial open channel and ground water hydrological processes. It summarises the modifications introduced in the traditional coupling techniques for stream-aquifer interaction in order to relax the simple assumption of rigid boundaries in alluvial rivers. The streambed thickness due to sedimentation $\left(Z_{1}\right)$ is represented individually from the aquifer thickness $\left(Z_{2}\right)$. In the event of aggradation, different hydraulic properties due to foreign sediment accumulations can be accounted for exclusively, by assigning $z_{1}$ and $\mathrm{k}_{1}$ with appropriate values. Even when the sediment deposit is washed away such that $Z_{1}=0$, the equation is still applicable, only that further erosion will be affecting the aquifer thickness $\left(\mathrm{Z}_{2}\right)$ itself.

The groundwater drainage flow into or out of the river can then be evaluated according to the following summarised procedure of MASAI:

The initial hydraulic conditions $\mathrm{H}^{\circ}, \mathrm{y}^{\circ}$ and $\mathrm{Z}_{1}{ }^{\circ}$ at time $\mathrm{t}^{0}$ are used to compute a steady seepage flow $\mathrm{q}^{\circ}$, which is applied in the routing solution to evaluate the new water conditions after a short time period Dt. At the next time $\mathrm{t}^{\mathrm{j}+1}$, the new values $\mathrm{H}^{1}$, $\mathrm{Z}_{1}{ }^{1}$ and $\mathrm{y}^{1}$, computed by the respective water routing, sediment routing and groundwater flow modules, are applied to compute the new groundwater transfer $\mathrm{q}^{1}$, for routing in the next time step. The procedure is then repeated until the total time period in consideration is covered.

\section{Verification of MASAI}

The procedure for verifying MASAI was based on two criteria to be satisfied:

- Application of MASAI to produce results that are comparable with other results simulated by accepted and published models.

- Application of MASAI to simulate events that have not been modelled with existing models.

The first criterion was accomplished by comparing results simulated by MASAI with other results from two examples of published schemes. Only the results are presented. Details of the modelling procedures of the examples can be found in the respective references.
The second criterion was achieved by applying MASAI to simulate the effects of variable sediment yields on baseflow.

\section{Comparison of simulated results}

The conceptual scheme described by Pinder and Sauer (1971) was modelled and MASAI was applied to simulate its stream-aquifer interaction processes. Swain and Wexler(1996) have also similarly used the same scheme to verify the MODBRANCH model.

In their modelling, Pinder and Sauer (1971) solved the continuity and momentum equations for one-dimensional, unsteady, uniform cross-section streamflow routing by an explicit finite-difference staggered-net method. The two-dimensional groundwater flow equation was solved by the iterative alternating direction implicit technique. The streamflow and groundwater equations were coupled by the leakage equation given in Eq. (7). Pinder and Sauer (1971) used the stream-aquifer interaction model to demonstrate how bank storage modifies the hydrograph of a flood event, by inputting a flood wave hydrograph at the upstream end of an initially steady river traversing an alluvial aquifer on a flood plain, and noting the effect on the flood hydrograph downstream. In one simulation the river bed is assumed to be impermeable (no stream-aquifer interaction) and in another it is assumed to be permeable (streamaquifer interaction permitted). Comparison of their results with those simulated by MASAI is presented graphically in Fig. 2a. It shows that, for practical purposes, MASAI can reproduce the results. The slight differences in the results could be because of the different numerical methods employed. Unlike the explicit finitedifference staggered-net method employed by Pinder and Sauer (1971), MASAI used the four-point implicit finite-difference method.

In the preceding example, only streamflow routing and its linkage with groundwater flow were verified. In the following example, verification for streamflow routing and its linkage with sediment routing will be presented. In this case the conceptual scheme by Chang and Richards (1971) was modelled and solved by the water and sediment routing solutions of MASAI. Chen (1973) has also used the same scheme for verification. Chang and Richards (1971) used the sediment routing model to demonstrate how sediments are deposited by transient flows, by allowing a sediment-laden flow to pass through a reservoir upstream of a dam, and noting the new bed elevation of the reservoir after the flow. A comparison of the results simulated by MASAI with those obtained by Chang and Richards (1971), and Chen (1973) is presented in Fig. 2b. Again, the slight differences in the results could be because of the different numerical methods employed.

The simulation results of the two schemes, Figs. $2 a$ and $2 b$, demonstrate that MASAI is capable of reproducing comparable and acceptable results. The first verification criterion is therefore assumed to have been satisfied.

\section{Simulation of the effects of variable sediment yield on baseflow recession}

In this verification, draining conditions of a river are generated in order to study the effects of sedimentation on baseflow recession. The numerical experiments were also based on the conceptual hydrological system defined by Pinder and Sauer (1971). Its flood plain extended $42672 \mathrm{~m}$ along the length of the channel and was $427 \mathrm{~m}$ across the valley. Impermeable materials surrounded it on all sides. The initial saturated thickness ranged from $67 \mathrm{~m}$ at the upstream boundary to $27 \mathrm{~m}$ at the downstream boundary. The streamflow was along the axis of the valley through a straight 
Figure 2a

Simulated flood hydrograph attenuation due to stream-aquifer interaction, at a location $15244 \mathrm{~m}$ from the upstream boundary

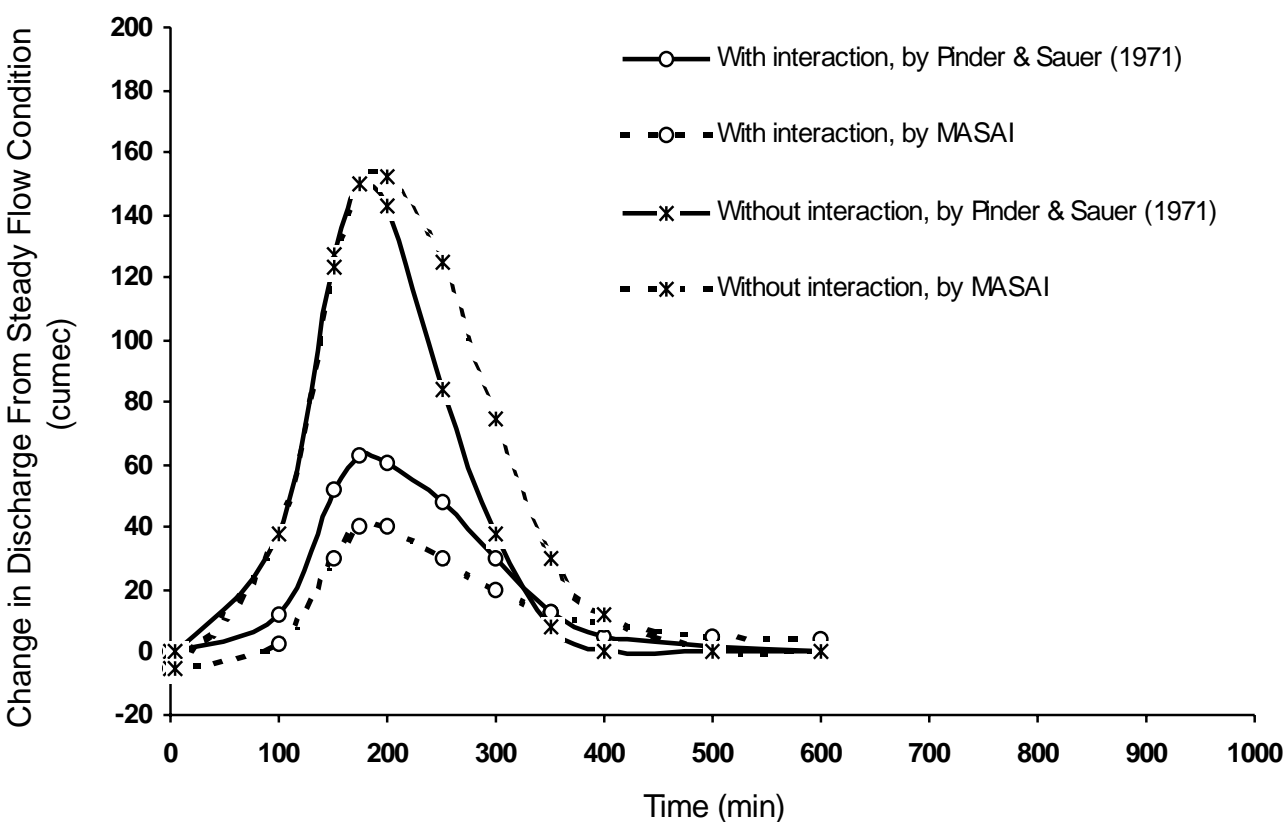

Figure $2 b$ Simulated bed elevation profiles upstream of a dam, after 30 min. of sediment-laden flow through a dam

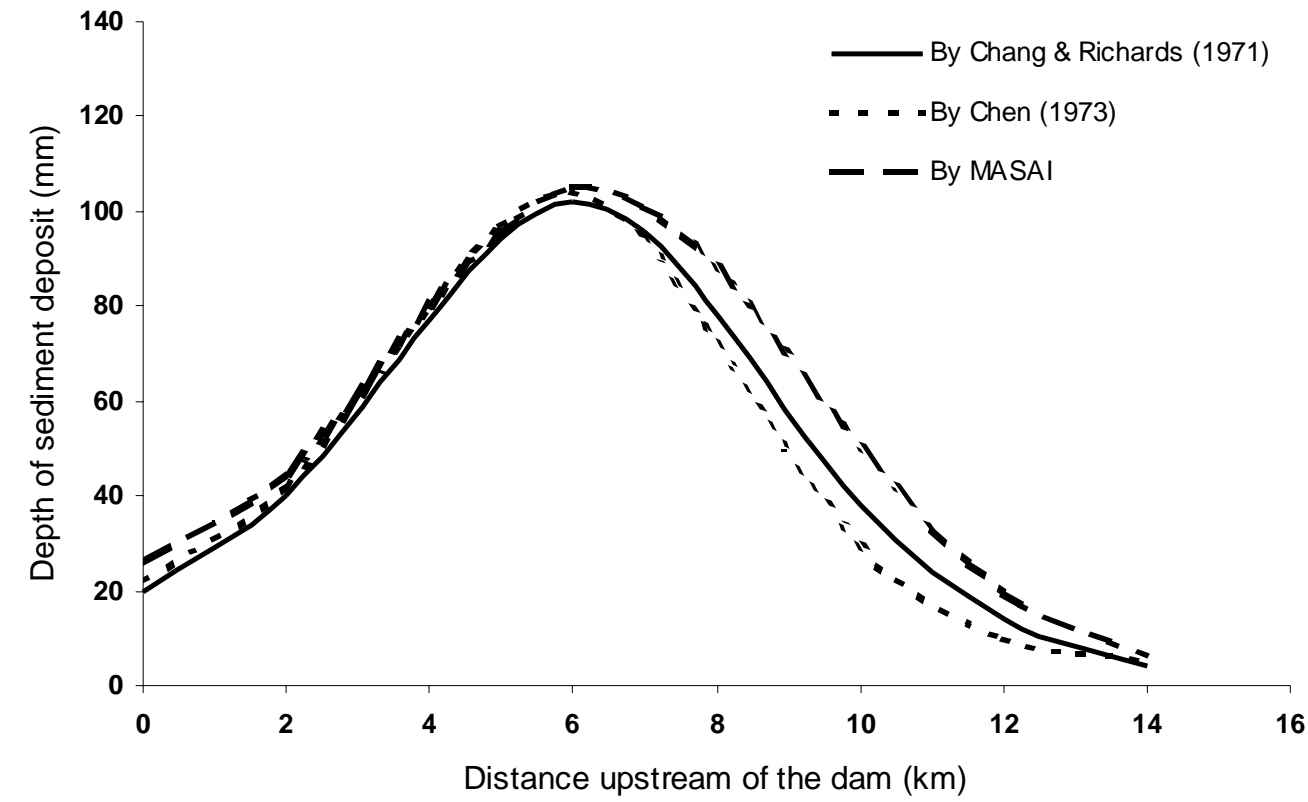

channel with a constant cross-section and a slope of 0.001 . The hydraulic conductivity of the aquifer (assumed homogeneous and isotropic) was 0.003 . The channel was $30 \mathrm{~m}$ wide and the initial depth of flow was $6 \mathrm{~m}$.

An inflow hydrograph was routed through the system by maintaining a flood flow of $500 \mathrm{~m}^{3} / \mathrm{s}$ for 3 days in order to acquire steady conditions, and then suddenly reducing the flow to a baseflow of $200 \mathrm{~m}^{3} / \mathrm{s}$, where it remained throughout the experiment. The river was subdivided into 10 shorter reach elements, and the exchange amounts were the net seepage flows from the surrounding aquifer into the river over each of the elements. The exchange amount, baseflow, is due to the hydraulic gradient created by the falling river stage, and will continue until the water table in the surrounding aquifer is equal to the water level in the river at the steady discharge flow rate of $200 \mathrm{~m}^{3} / \mathrm{s}$. By modelling the system responses under these conditions it was possible to isolate and study the behaviour of baseflow recession curves at any desired location. Results illustrated by the recession curves in Figs. $3 \mathrm{a}$ and
$3 \mathrm{~b}$ are for the downstream boundary section, and are typical of those obtained using any combination of the system parameters, only that the curvature will vary with every different combination of the parameters. In the presentations, the baseflow discharges are plotted against the time elapsed since the upstream flood flow was suddenly reduced from 500 to $200 \mathrm{~m}^{3} / \mathrm{s}$.

It is noted from the figures that different sedimentation parameters produced different rates of baseflow recession curves. In addition, the numerical experiments also demonstrated that the simulated curves (Fig. 3a), which in this case included sediment routing effects, did conform to the standard exponential decay curve relationship given by Eq. (1). The first set of results (Fig. 3a) was obtained by holding the input sediment concentration at 5000 $\mathrm{mg} / \ell$, while varying the hydraulic conductivity of the sediment layer at the bottom of the river between 0.0 and $0.0001 \mathrm{~m} / \mathrm{s}$.

In the second experiment (Fig. 3b), the hydraulic conductivity of the sediment layer was held at $0.0001 \mathrm{~m} / \mathrm{s}$, while the sediment yield input into the system was varied between 0 and 25500 


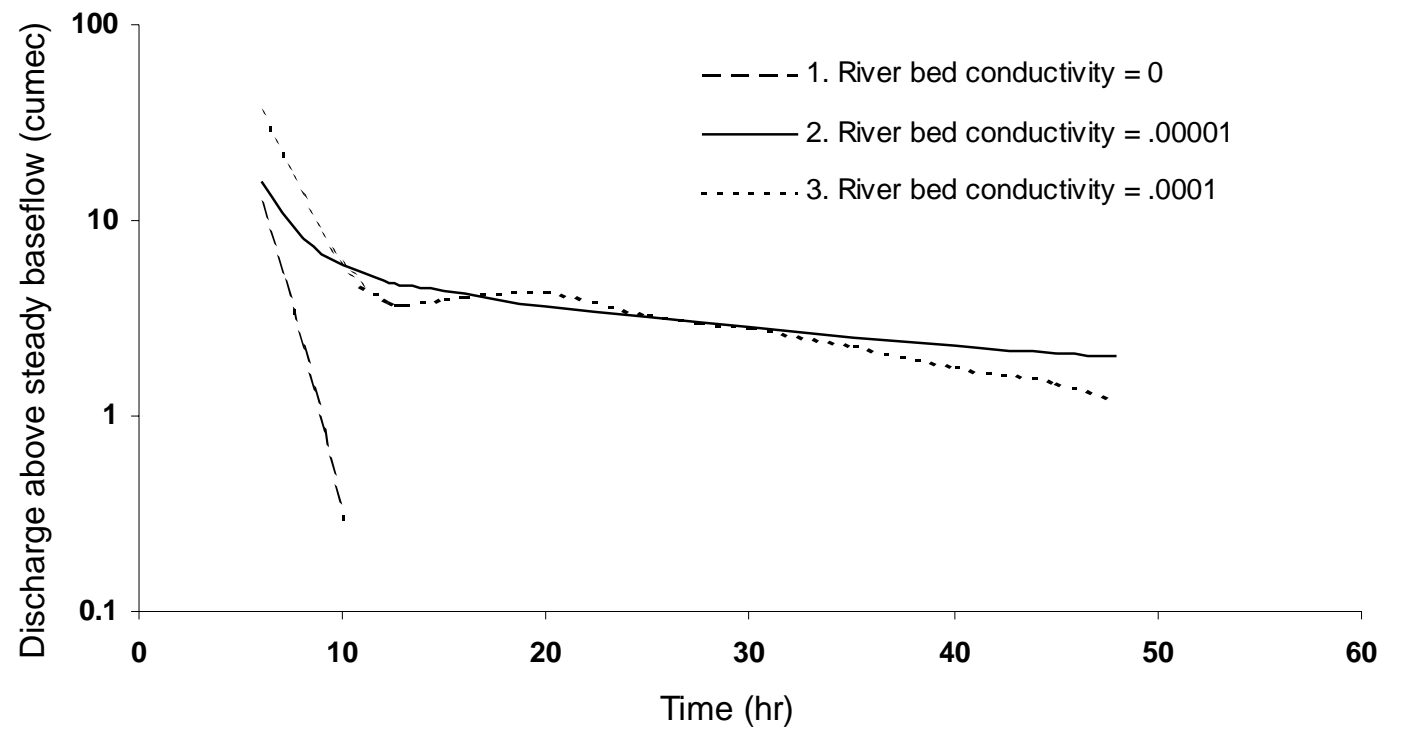

Figure 3a

Baseflow recession curves at the downstream station resulting from various hydraulic conductivity of the river bed

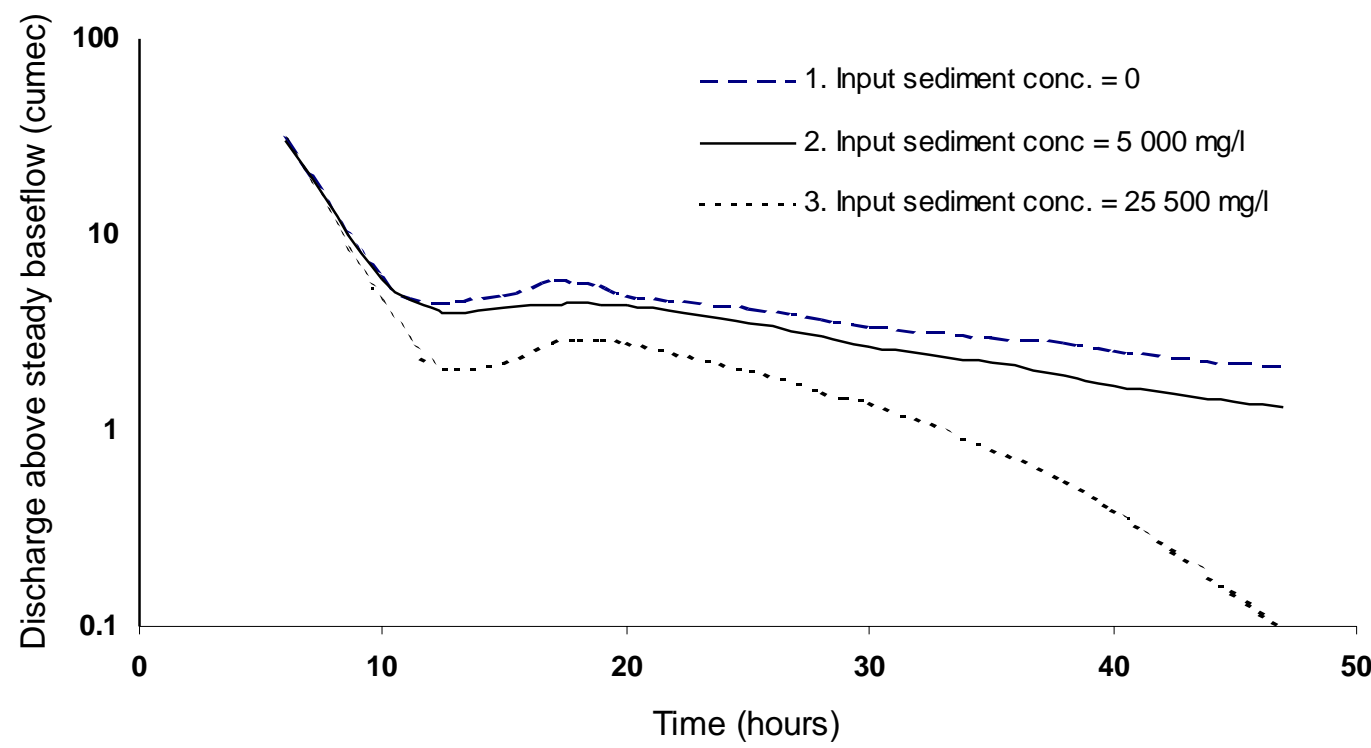

$\mathrm{mg} / \ell$. Where the hydraulic conductivity of zero is assumed for the riverbed, it means that groundwater seepage contribution from the surrounding aquifer is precluded, and only channel flow is considered. Without groundwater contribution, therefore, the minimum flow condition of $200 \mathrm{~m}^{3} / \mathrm{s}$ reached the downstream end after about $12 \mathrm{~h}$ since it was introduced at the upstream end of the system.

To interpret the results, it may be helpful to recall Eq. (12), which describes the derived coupling formula for unstable alluvial stream-aquifer interacting systems. In Fig. 3a, for instance, with the hydraulic conductivity of $0.00001 \mathrm{~m} / \mathrm{s}$, the rate of baseflow recession is relatively less than when the hydraulic conductivity is $0.0001 \mathrm{~m} / \mathrm{s}$, because of the higher seepage resistance across the interface sediment layer. Note that the rate of groundwater depletion (baseflow recession) is most clearly seen after the passage of the channel storage - after about $12 \mathrm{~h}$. The slight rise in the recession curve around the 18th hour indicates the time of concentration, when the maximum groundwater contribution from the banks arrived at the downstream station, arriving much later after the channel storage had ceased around the 12th hour.

The effects of river bed sedimentation on baseflow recession is more evident from simulation results of different input sediment yields into the channel reach. When the input sediment load is higher than the sediment transport capacity of the channel reach, some of the sediments are deposited on the river bed. As the thickness (level) of the sediment layer at the bottom of the river is raised, through sediment deposition, the corresponding hydraulic gradient driving seepage from surrounding aquifers towards the river is decreased. With higher sediment input (Qs $=25500 \mathrm{mg} / \ell$ ), therefore, less groundwater is drained from the surrounding aquifers because of an induced faster rate of build-up of the sediment layer barrier on the river bed. In this example, (line 3, Fig. 3b) groundwater seepage contribution from the banks was almost negligible by the 48th hour. It is also worthwhile to note that with the higher sediment concentration, the baseflow recession curve no longer conformed to the standard logarithmic decay curve.

Singh (1968), demonstrated similar findings for a river that was continuously losing water into adjacent aquifers. He did analytical studies on the effect of aquifer leakage as a result of high groundwater withdrawal, evaporation or deep percolation leakage conditions. He demonstrated that the traversing river became more and more influent, resulting in baseflow recession curves that were steeply deviating from the traditional exponential relationship. Here the deviation emanates from the rising river bed, which correspondingly increases the river stage and the hydraulic gradient towards the aquifer, causing the river to become less and less effluent, presenting 
the same feature of steeply deviating recession curve away from the usual exponential relationship. Problems associated with these types of changes include development of water-logged riparian conditions, declining streamflow discharges in downstream reaches, among others.

When the sediment yield into the reach is lower than the sediment transport capacity ( in this case $\mathrm{Q}_{\mathrm{s}}=0$ ), the bed is scoured. As the level of the river bed is lowered, through erosion, the corresponding hydraulic gradient driving water from surrounding aquifers towards the river is increased. More groundwater, therefore, is drained from the surrounding aquifers because of the falling river stage induced by river-bed erosion. In this example (line 1, Fig. 3b) groundwater seepage contribution from the banks was almost steady (not decreasing any more) at about $3 \mathrm{~m}^{3} / \mathrm{s}$ above the steady flow by the 48th hour. It is also worthwhile to notice that with low sediment yield, the baseflow recession curve also no longer conformed to the standard decay curve of Eq. (1).

Singh (1968) also produced similar results for an aquifer that was gaining more water from other sources, like precipitation and infiltration from irrigation canals. He demonstrated that baseflow recession curves of such systems deviated from the theoretical exponential relationship by becoming flatter as the river became more and more effluent. In this case, it is due to river bed degradation, lowering the river stage, and therefore intensifying the hydraulic gradient towards the river. Such conditions will favour depletion of surrounding aquifers, causing the baseflow recession curve to deviate from the standard decay relationship, but this time becoming flatter as the river becomes more and more effluent. Problems associated with such types of changes include excessive depletion of riparian groundwater reserves, instability of riverbanks and neighbouring infrastructure, besides others.

\section{Conclusions}

An enhanced procedure for coupling alluvial stream-aquifer interacting systems has been developed. The modified solution procedure has more physical sense in erodable alluvial channels that carry sediment-laden flows. In such systems, coupling of streamflow and groundwater by purely empirical relationships, as are often used for estimating baseflow, does not particularly interpret the operative physical processes. Use of lumped modelling techniques eliminates many of the problems involved in making assumptions, but gives little insight into the hydrological and fluvial processes involved in unstable alluvial stream-aquifer interacting systems. The significant feature of the modelling procedure developed here, therefore, is its extra capability to track time-dependent aggradation and degradation of the river bed and their corresponding hydrological effects.

The need to test whether a modelling procedure replicates event processes that have been observed in the real world is acknowledged. However, given the paucity of observed data on unstable alluvial stream-aquifer processes, this study did not necessarily endeavor to go all the way to produce a final product and test the accuracy of its simulated results. Rather, simple conceptual models have been used to afford an experimental orientation in which to contemplate the consequences of an unsteady linkage conductance layer at the bottom of a river that is hydraulically connected to aquifers. In this way, at least, model developers and users are offered an opportunity to explore further their mental models and the consequences of land use (or river engineering) changes, and to engage in deeper conversations about fundamental but often overlooked prerequisites for studying alluvial streamaquifer interactions.

\section{Acknowledgements}

The original research work for this paper was made possible by the financial support of the British Council and Rank Xerox Offices of Nairobi, Kenya. They funded the main $\mathrm{PhD}$ research programme in the UK and the fieldwork studies in Kenya. Resources at the University of Zululand, and later at the Department of Water Affairs and Forestry (DWAF), Pretoria, facilitated the publication of the paper. The author is grateful to all for the support.

\section{References}

ACKERS P and WHITE WR (1973) Sediment transport: New approach and analysis. J. Hydraul. Div. ASCE 99 (HY11) 2041-2060.

AMEIN M and FANG SC (1970) Implicit flood routing in natural channels. J. Hydraul. Div. ASCE 96 (HY12) 2481-2501.

BEAR J (1972) Dynamics of Fluid in Porous Media. American Elsevier, New York.

CHANG HH(1982) Mathematical model for erodible channels. J. Hydraul. Div. ASCE 108 (HY5) $678-689$.

CHANG HH (1988) Fluvial Processes in River Engineering. John Wiley and Sons, New York.

CHANG FF and RICHARDS DL (1971) Deposition of sediment in transient flow. J. Hydraul. Div. ASCE 97 (HY6) 837-849.

CHEN YH(1973) Mathematical Modelling of Water and Sediment Routing in Natural Channels. PhD. Thesis, Civil Eng. Dept. Colorado State Univ., USA.

CHOW V, MAIDMENT DR AND MAYS LW (1988) Applied Hydrology. McGraw-Hill Book Company, New York.

CRERAR S, FRY RG, SLATER PM, VAN LANGENHOVE G and WHEELER D (1988) An unexpected factor affecting recharge from ephemeralriver flow in SWA/Namibia. In: Simmers I(ed.) Estimation of Natural Groundwater Recharge. D. Reidel Publishing Company. 11-28.

CUNNINGHAM AB and SINCLAIR PJ (1979) Application and analysis of a coupled surface and ground water model. J. Hydrol. 43 129-148.

HUGHES DA and SAMI K (1992) Transmission losses to alluvial and associated moisture dynamics in a semi-arid ephemeral channel system in Southern Africa. Hydrol. Processes 6 45-53.

MWAKA BML (1995) Analysis of the Hydrological Impacts Due to Sedimentation Variability on Alluvial Stream-Aquifer Systems. PhD Thesis, Civil Eng. Dept., Univ. of Newcastle Upon Tyne, UK.

PETTS G and FOSTER I (1992) Rivers and Landscape. Edward Arnold, London

PINDER GF and SAUER SP (1971) Numerical simulation of flood wave modification due to bank storage effects. Water Resour. Res. 7 (1) 63 70.

SHARP JM (Jr.) (1977) Limitations of bank-storage model assumptions. J. Hydrol. 35 31-47.

SINGH KP (1968) Some factors affecting baseflow. Water Resour. Res. 4 (5) 985-999.

STRELKOFF T (1969) The one-dimensional equation of open channel flow. J. Hydraul. Div. ASCE 95 (HY3) 861-876.

SWAIN ED and WEXLER EJ (1996) A Coupled Surface-Water and Ground-WaterFlow Model(MODBRANCH) for Simulation of StreamAquifer Interaction. Techniques of Water-Resources Investigations of the USGS, Book 6. Washington.

TODD DK (1955) Groundwater flow in relation to a flooding stream. ASCE Proc. 81 628-1 - 628-20.

WANG H and ANDERSON MP (1982) Introduction to Groundwater Modelling: Finite Difference and Finite Element Methods. WH Freeman, San Francisco.

YOUNGER PL, MACKAY R and CONNORTON BJ (1993) Streambed sediment as a barrier to groundwater pollution: Insights from fieldwork and modelling the river Thames basin. J. Inst. Water Environ. Manage. 7 (6) $576-585$. 